\title{
Simultaneous TG, DTG and DTA Studies on Manganese Oxides
}

\author{
By R. D. Agrawa1*
}

\begin{abstract}
Using a derivatograph, the temperatures and heats of decomposition of $\mathrm{MnO}_{2}$ and $\mathrm{Mn}_{2} \mathrm{O}_{3}$ as well as the temperature and heat of transformation of $\mathrm{Mn}_{3} \mathrm{O}_{4}$ have been studied. Using $\mathrm{CaCO}_{3}$ as standard, the heat of decomposition of $\mathrm{MnO}_{2}$ to $\mathrm{Mn}_{2} \mathrm{O}_{3}$ has been determined to be $25.56 \pm 1.67$ $\mathrm{kJ} / \mathrm{mol}$ of $\mathrm{MnO}_{2}$, and that of decomposition of $\mathrm{Mn}_{2} \mathrm{O}_{3}$ to $\mathrm{Mn}_{3} \mathrm{O}_{4}$ to be $15.94 \pm 2.09 \mathrm{~kJ} / \mathrm{mol}$ of $\mathrm{Mn}_{2} \mathrm{O}_{3}$. The temperatures of decomposition of $\mathrm{MnO}_{2}$ and $\mathrm{Mn}_{2} \mathrm{O}_{3}$ to lower oxides, namely, $\mathrm{Mn}_{2} \mathrm{O}_{3}$ and $\mathrm{Mn}_{3} \mathrm{O}_{4}$ respectively, have been found to be $843 \pm 5 \mathrm{~K}$ and $1263 \pm 5 \mathrm{~K}$ respectively under atmospheric conditions. It has been confirmed that $\mathrm{Mn}_{3} \mathrm{O}_{4}$ undergoes a crystalline transformation during cooling at $1453 \pm 5 \mathrm{~K}$ with $4.35 \pm 0.04 \mathrm{~kJ} / \mathrm{mol}$ of $\mathrm{Mn}_{3} \mathrm{O}_{4}$ as the heat of transformation.
\end{abstract}

(Received November 4, 1980)

\section{Introduction}

The system $\mathrm{Mn}-\mathrm{O}$ is of considerable economic importance. In addition to the role of manganese as an alloying element in steel and non-ferrous alloys, it is a vital element, used for control of sulphur in steel-making and also the most commonly and widely used deoxidiser for molten steel. The oxide, so formed, constitutes a part of the slag, and this in turn may have a serious fluxing effect on the furnace refractories. Non-metallic uses of manganese ores in dry batteries and chemical compounds, in glass to neutralise the effect of iron and as a colouring agent in ceramics have also stimulated considerable interest in the $\mathrm{Mn}-\mathrm{O}$ system. In recent years, the intermediate oxides, $\mathrm{Mn}_{2} \mathrm{O}_{3}$ and $\mathrm{Mn}_{3} \mathrm{O}_{4}$, have also gained commercial importance. Consequently it is of interest to determine if either of these oxides can be obtained in relatively pure form as a decomposition product of manganese dioxide. The different needs of manganese have therefore caused a great deal of attention to be devoted to its effective utilisation and improved recovery from its ores and slags. For a scientific investigation of all these problems, a knowledge of the system $\mathrm{Mn}-\mathrm{O}$ is necessary.

Data reported in the literature on the temperature and heats of decomposition of different

* Department of Metallurgical Engineering, University of Roorkee, Roorkee-247672, India. manganese oxides, as obtained by different investigators are summarised in Table 1, which clearly shows an appreciable variation in these values. It is also seen that in most of these investigations, separate and independent studies for the temperatures and heats of decomposition have been carried out. Therefore, it was thougth desirable to check the reliability of the data reported using a derivatograph which can simultaneously obtain DTA, DTG, TG and $T$ curves and thus permit a simultaneous determination of both the temperatures and heats of decomposition of different manganese oxides under a given set of experimental conditions.

\section{Experimental}

For the present investigation, a derivatograph described by Paulik et al. ${ }^{(10)}$ has been used. Figure 1 shows its construction and principle of operation. It records the TG curve photographically. A light signal indicating the deflection of the balance is projected onto photosensitive paper. On one end of the beam a coil is hung which moves (when the beam moves) in a homogeneous field set-up by permanent magnets. The light signal from a galvanometer connected to the ends of the coil records the DTG curve on the photo-sensitive paper. At the same time the derivatograph also operates as a DTA instrument. The sample and inert reference substance are contained in platinum crucibles of a special shape, and counterconnected thermocouples are placed in the 
Table 1 Heat and temperature of decomposition of manganese oxides.

\begin{tabular}{|c|c|c|c|c|c|}
\hline \multirow{2}{*}{ Source } & \multirow{2}{*}{$\begin{array}{l}\text { Method used } \\
\text { for investigation }\end{array}$} & \multicolumn{2}{|c|}{$\begin{array}{l}\text { Heat of decomposition in } \\
\mathrm{kJ} / \mathrm{mol} \text { of reactant }\end{array}$} & \multicolumn{2}{|c|}{ Temperature of decomposition $(\mathbf{K})$} \\
\hline & & $\mathrm{MnO}_{2} \rightarrow \mathrm{Mn}_{2} \mathrm{O}_{3}$ & $\mathrm{Mn}_{2} \mathrm{O}_{3} \rightarrow \mathrm{Mn}_{3} \mathrm{O}_{4}$ & $\mathrm{MnO}_{2} \rightarrow \mathrm{Mn}_{2} \mathrm{O}_{3}$ & $\mathrm{Mn}_{2} \mathrm{O}_{3} \rightarrow \mathrm{Mn}_{3} \mathrm{O}_{4}$ \\
\hline $\begin{array}{l}\text { Wicks and } \\
\text { Block }^{(1)} \\
\text { Meyer and }^{-}\end{array}$ & Calorimetric & $41.0 \pm 5.0$ & - & 一 & - \\
\hline $\begin{array}{l}\text { Rotgers } \\
\text { Kapustinsky and }\end{array}$ & Equilibrium & 60.46 & 23.22 & 803 & 1213 \\
\hline Bayushkina $^{(3)}$ & Equilibrium & 32.93 & - & - & - \\
\hline $\mathrm{Otto}^{(4)(5)}$ & Equilibrium & 39.58 & 28.70 & 697 & 1144 \\
\hline Honda and & Magnetic & & & & \\
\hline $\begin{array}{l}\text { Sone }^{(6)} \\
\text { McMurdie and }\end{array}$ & $\begin{array}{l}\text { susceptibility } \\
\text { Differential }\end{array}$ & 一 & - & 808 & 1206 \\
\hline Golovato $^{(7)}$ & thermal analysis & - & - & 943 & 1243 \\
\hline $\begin{array}{l}\text { Matsushima and } \\
\text { Thoburn }^{(8)} \\
\text { Kulp and }\end{array}$ & $\begin{array}{l}\text { Differential } \\
\text { thermal analysis } \\
\text { Differential }\end{array}$ & $26.99 \pm 1.67$ & $17.61 \pm 2.93$ & 835 & 1200 \\
\hline Perfetti $^{(9)}$ & thermal analysis & 一 & - & $853 \sim 943$ & 1278 \\
\hline Present work & $\begin{array}{l}\text { Differential } \\
\text { thermal analysis }\end{array}$ & $25.56 \pm 1.67$ & $15.94 \pm 2.09$ & $843 \pm 5$ & $1263 \pm 5$ \\
\hline
\end{tabular}

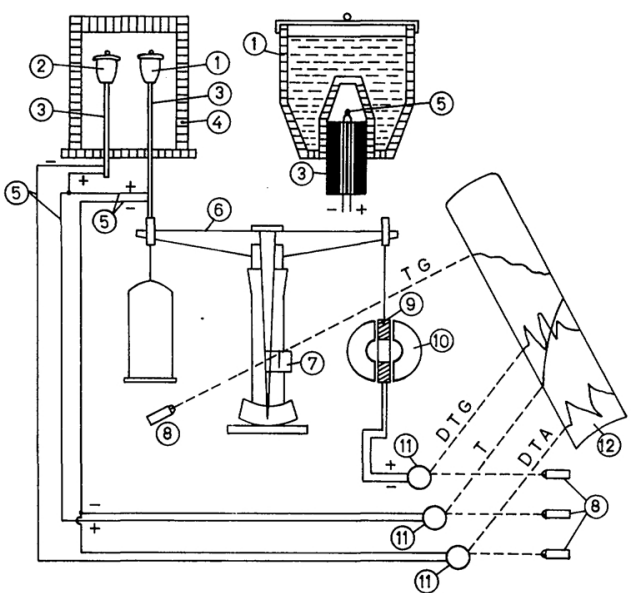

1. Crucible for the sample, 2. Crucible for the iner substance, 3. Porcelain tube, 4. Electric furnace, 5. Thermocouple, 6. Balance, 7. Optical slit, 8. Lamp 9. Coil, 10. Permanent magnet, 11. Galvanometer, 12. Pnotographic paper.

Fig. 1 Schematic sketch showing the principle of the derivatograph. (1) Crucible for the sample, (2) Crucible for the inert substance, (3) Porcelain tube, (4) Electric furnace, (5) Thermocouple, (6) Balance, (7) Optical slit, (8) Lamp, (9) Coil, (10) Permanent magnet, (11) Galvanometer, (12) Photographic paper.

re-entrants in the bottom of the crucibles. A galvanometer in the thermocouple circuit measures the temperature difference between the sample and the reference substance (DTA curve), while another connected to the sample thermocouple indicates the temperature of the sample ( $T$ curve). The instrument carries a voltage stabiliser unit and a temperature controlling device. It permits accurate control of temperature to $\pm 5 \mathrm{~K}$ and accurate weighing to $\pm 1.0 \mathrm{mg}$. For getting a derivatogram, first the photographic paper on the recording drum was ruled for $6 \mathrm{~min}$ after adjusting the position of the recorder to the maximum temperature desired. Then after the zero adjustment with

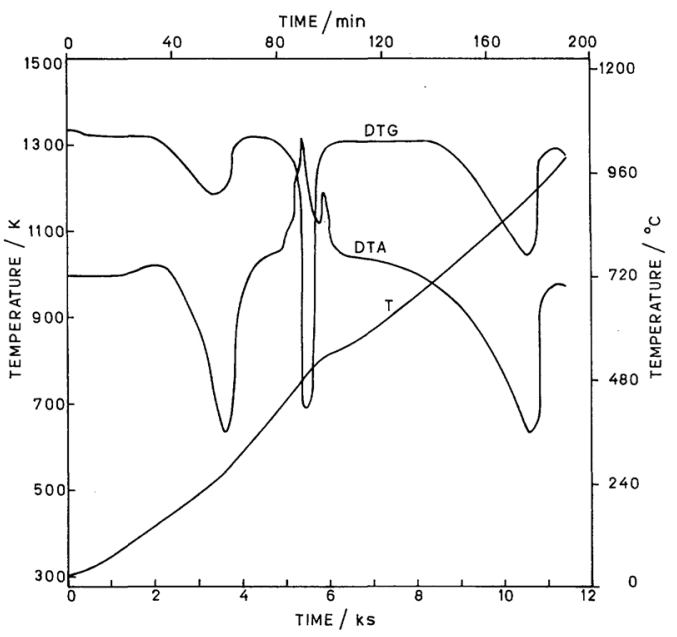

Fig. 2 Typical DTA, DTG and T curves for decomposition of $\mathrm{CaC}_{2} \mathrm{O}_{4} \cdot \mathrm{H}_{2} \mathrm{O}$ (mass: $0.750 \mathrm{~g}$ ). 
the empty platinum crucible, the crucible was filled with the moisture-free sample to the same volume as the alumina powder reference material in the other platinum crucible and weighed to $\pm 1.0 \mathrm{mg}$. The furnace was put in position, room temperature adjusted and heating programme $\left(0.1 \mathrm{~K} / \mathrm{s}\right.$ or $\left.6^{\circ} \mathrm{C} / \mathrm{min}\right)$ set. The actual experiment was then started.

For experimental studies, micro-analytical reagent grade $\mathrm{MnO}_{2}$ was used and the lower oxides of manganese, namely, $\mathrm{Mn}_{2} \mathrm{O}_{3}$ and $\mathrm{Mn}_{3} \mathrm{O}_{4}$ were produced by decomposing this $\mathrm{MnO}_{2}$ at 1153 and $1373 \mathrm{~K}$ respectively for 172.8 $\mathrm{ks}(48 \mathrm{~h})$ in each case. For calculation of heat change per unit area under DTA peak, analytical reagent grade calcium oxalate was used. The samples used in the test had particle size in the range 74 to $52 \mu \mathrm{m}$.

\section{Results and Discussions}

The derivatogram obtained for the decomposition of calcium oxalate is shown in Fig. 2. Peaks in the DTA curves above the base line are exothermic peaks and those below this base line, endothermic peaks. The first endothermic peak under DTA in this figure corresponds to the decomposition of $\mathrm{CaC}_{2} \mathrm{O}_{4}$. $\mathrm{H}_{2} \mathrm{O}$ to $\mathrm{CaC}_{2} \mathrm{O}_{4}$ and the second to the decomposition of $\mathrm{CaCO}_{3}$ to $\mathrm{CaO}$ and $\mathrm{CO}_{2}$. Using standard data ${ }^{(11)}$ on the heat of decomposition of $\mathrm{CaCO}_{3}$ at $1173 \mathrm{~K}$-the decomposition temperature of $\mathrm{CaCO}_{3}$ as obtained from the DTA and $\mathrm{T}$ curves of Fig. 2, and also from a knowledge of the mass of $\mathrm{CaCO}_{3}$ present in the sample of $\mathrm{CaC}_{2} \mathrm{O}_{4} \cdot \mathrm{H}_{2} \mathrm{O}$ used for plotting this derivatogram and the area under the second endothermic peak of the DTA curve in Fig. 2, the heat change per unit area under DTA curve has been calculated and found to be $0.7058 \mathrm{~J}$. This data has been subsequently used for calculation of the heat changes in the decomposition of different manganese oxides.

The derivatogram obtained for the decomposition of $\mathrm{MnO}_{2}$ to $\mathrm{Mn}_{2} \mathrm{O}_{3}$ and then to $\mathrm{Mn}_{3} \mathrm{O}_{4}$ using the same sample is shown in Fig. 3. Area of the DTA curve under the first endothermic peak in this figure represents the heat of decomposition of $\mathrm{MnO}_{2}$ to $\mathrm{Mn}_{2} \mathrm{O}_{3}$ and that under the second endothermic peak corresponds to the heat of decomposition of $\mathrm{Mn}_{2} \mathrm{O}_{3}$ to $\mathrm{Mn}_{3} \mathrm{O}_{4}$. From a knowledge of the heat change per unit area obtained from the above referred calibration run using calcium carbonate, the heats of decomposition of $\mathrm{MnO}_{2}$ to $\mathrm{Mn}_{2} \mathrm{O}_{3}$ and of $\mathrm{Mn}_{2} \mathrm{O}_{3}$ to $\mathrm{Mn}_{3} \mathrm{O}_{4}$ have been calculated and presented in Table 1 . It is seen from this table that the results of the present investigation on heat of decomposition are in close agreement with only the results of Matsushima and Thoburn ${ }^{(8)}$. It may be mentioned here that the values obtained by equilibrium technique have to be relied upon with some reservations because equilibrium is likely to take unduly long time. Moreover, effect of stoichiometry cannot be neglected. The actual chemical formula of manganese dioxide used in the present investigation was found to be $\mathrm{MnO}_{1.96}$.

The derivatogram obtained for the determination of temperatures and heat changes of structural transformation in $\mathrm{Mn}_{3} \mathrm{O}_{4}$ on heating and cooling are shown in Fig. 4. The first

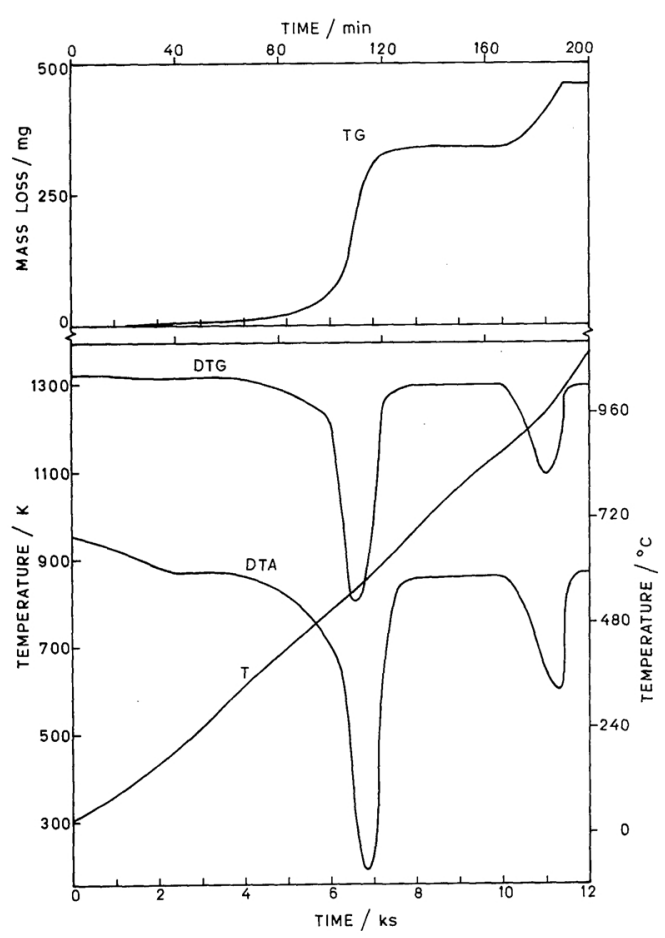

Fig. 3 Typical DTA, DTG, TG and $\mathrm{T}$ curves for decomposition of $\mathrm{MnO}_{2}$ to $\mathrm{Mn}_{2} \mathrm{O}_{3}$ and then to $\mathrm{Mn}_{3} \mathrm{O}_{4}$ (mass: $4.00 \mathrm{~g}$ ). 
Table 2 Temperature and heat of structural transformation in $\mathrm{Mn}_{3} \mathrm{O}_{4}$.

\begin{tabular}{|c|c|c|}
\hline Source & Temperature (K) & $\begin{array}{l}\text { Heat of transformation } \\
\left(\mathrm{kJ} / \mathrm{mol} \text { of } \mathrm{Mn}_{3} \mathrm{O}_{4}\right)\end{array}$ \\
\hline Southard and Moore ${ }^{(12)}$ & $1445 \pm 40$ & - \\
\hline \multirow[t]{2}{*}{ McMurdie and Golovato( ${ }^{(7)}$} & 1443 (upon heating) & - \\
\hline & 1373 (upon cooling) & - \\
\hline $\operatorname{Kelley}^{(13)}$ & 1445 & $20.9 \pm 1.26$ \\
\hline Van Hook and Keith ${ }^{(14)}$ & $1433 \pm 5$ & - \\
\hline \multirow[t]{2}{*}{ Present work } & $1473 \pm 5$ (upon heating) & $5.73 \pm 1.26$ \\
\hline & $1453 \pm 5$ (upon cooling) & $4.35 \pm 0.04$ \\
\hline
\end{tabular}

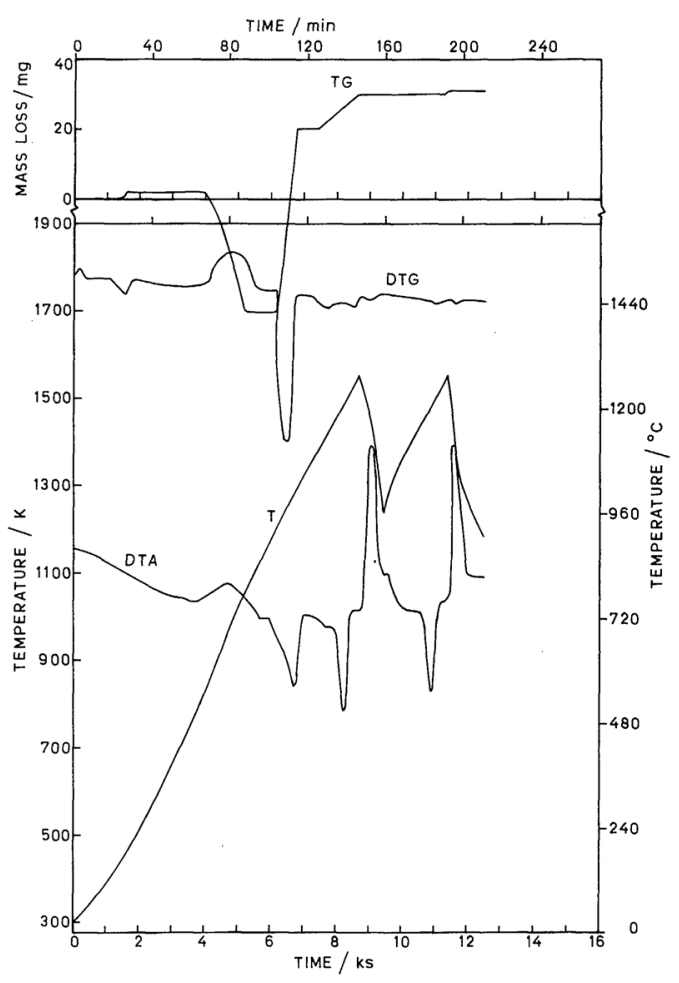

Fig. 4 Typical DTA, DTG, TG and T curves for structural transformation in $\mathrm{Mn}_{3} \mathrm{O}_{4}$ (mass: $4.00 \mathrm{~g}$ ).

endothermic peak in the DTA curve of this figure is due to the sudden decomposition of some residual $\mathrm{Mn}_{2} \mathrm{O}_{3}$ which might have been present in the sample of $\mathrm{Mn}_{3} \mathrm{O}_{4}$. The next two DTA endothermic peaks indicate the heat changes of structural transformation in $\mathrm{Mn}_{3} \mathrm{O}_{4}$ during heating, while the other two exothermic DTA peaks refer to the heat changes of the structural transformation in $\mathrm{Mn}_{3} \mathrm{O}_{4}$ during cooling. The average value of heat of structural transformation in $\mathrm{Mn}_{3} \mathrm{O}_{4}$ has been found to be $5.73 \pm 1.26 \mathrm{~kJ} / \mathrm{mol}$ of $\mathrm{Mn}_{3} \mathrm{O}_{4}$ at $1473 \pm 5 \mathrm{~K}$ during heating and $4.35 \pm 0.04 \mathrm{~kJ} / \mathrm{mol}$ of $\mathrm{Mn}_{3} \mathrm{O}_{4}$ at $1453 \pm 5 \mathrm{~K}$ during cooling. These results are reported in Table 2 for a comparison with data reported in literature. It is seen from this table that while the temperature of structural transformation in $\mathrm{Mn}_{3} \mathrm{O}_{4}$ is in close agreement with the reported value in literature, the heat of structural transformation in $\mathrm{Mn}_{3} \mathrm{O}_{4}$ obtained in the present investigation is appreciably different than the data reported by Kelley ${ }^{(13)}$, which is the only data available in the literature.

\section{Acknowledgements}

The author wishes to accord his indebtedness to Prof. V. B. Tare and Prof. P. M. Prasad of Department of Metallurgical Engineering at B. H. U., Varanasi, for their able guidance and help rendered during this investigation and he is also grateful to Dr. M. L. Kapoor, Professor of Extractive Metallurgy and Shri V. N. S. Mathur, Reader, at University of Roorkee, Roorkee for the useful discussion and help he obtained during the preparation of this paper.

\section{REFERENCES}

(1) C. E. Wicks and F. E. Block: U.S. Bur. Mines Bull., No. 605 (1963).

(2) R. J. Meyer and K. Rotgers: Z. Anorg. Chem., 57 (1908), 104.

(3) A. F. Kapustinsky and K. S. Bayushkina: J. Phys. Chem., 11 (1938), 77.

(4) E. M. Otto: J. Electrochem. Soc., 111 (1964), 89.

(5) E. M. Otto: ibid., 112 (1965), 98.

(6) K. Honda and T. Sone: Sci. Rep., Tohoku Imp. Univ., 3 (1914), 139.

(7) H. F. McMurdie and E. Golovato: J. Res. Natl. Bur. Std., 41 (1948), 589.

(8) T. Matsushima and W. J. Thoburn: Canad. J. Chem., 43 (1965), 1723.

(9) L. Kulp and J. Perfetti: Mineralog. Mag., 29 (1952), 239. 
(10) F. Paulik, J. Paulik and L. Erdey: Derivatograph, Typ. 0D-102, Hungary, (1968), p. 37.

(11) O. Kubaschewski, E. L. L. Evans and C. B. Alcock: Metallurgical Thermochemistry, Pergamon Press, New York, (1967), p. 312.

(12) J. C. Southard and G. E. Moore: J. Am. Chem.
Soc., 64 (1942), 1769.

(13) K. K. Kelley: U.S. Bur. Mines Bull., No. 476 (1949).

(14) H. J. Van Hook and M. L. Keith: Am. Mineralogist, 43 (1958), 69. 